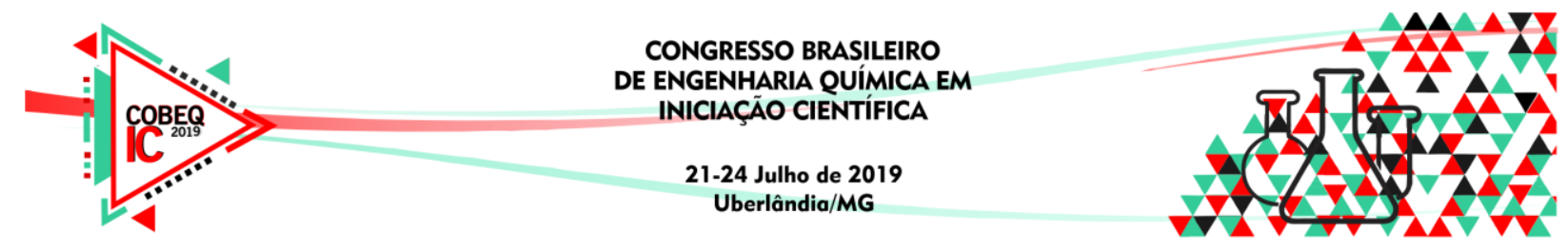

\title{
AVALIAÇÃO DA APLICAÇÃO DA ENZIMA TRANSGLUTAMINASE SOBRE AS CARACTERÍSTICAS DE SORVETES COM BAIXO E ALTO TEOR DE GORDURA
}

\author{
I. S. SILVA ${ }^{1}$, M. G. SOARES ${ }^{1}$ e V. C. R. SCHMIDT ${ }^{1}$ \\ ${ }^{1}$ Universidade Federal de Uberlândia, Faculdade de Engenharia Química \\ E-mail para contato: vivian@feq.ufu.br
}

\begin{abstract}
RESUMO - Em vista da ampla demanda e da conscientização dos consumidores quanto ao consumo de alimentos mais saudáveis, alternativas para a produção de sorvete é a redução de níveis de gordura e açúcar. Porém, essas reduções podem afetar diretamente a sua qualidade, ocasionando alterações nas propriedades físicas e sensoriais. A fim de preservar tais características, estudos estão voltados para a aplicação de aditivos no sorvete, como a enzima transglutaminase (TG). O efeito da enzima MTGase foi estudado sobre as características de sorvetes com baixo e alto teor de gordura.
\end{abstract}

\section{INTRODUÇÃO}

O sorvete é um produto amplamente consumido, classificado como sobremesa láctea congelada. Essa classificação varia de acordo com sua formulação, composição e diferentes processamentos (GOFF; HARTEL, 2013). De acordo com a RDC n²67 (BRASIL, 2003) sorvete é definido como produto congelado obtido a partir de uma emulsão de gorduras e proteínas; ou de uma mistura de água e açúcares.

Um dos principais ingredientes envolvidos na produção de sorvete é o leite, composto de carboidratos, proteínas e lipídeos. No qual as proteínas representam de 4 a $5 \%$ dessa composição, sendo que as proteínas presentes são as caseínas e as proteínas do soro (lactoalbumina e lactoglobulina), as quais contribuem para a coalescência parcial, conduzindo o aumento da aeração e da estabilidade da espuma (ROSSA, 2010).

No processo de produção de sorvete light a substituição de gordura ou açúcares podem interferir negativamente na qualidade final do sorvete, em relação a cremosidade, textura, aeração e estabilidade da espuma (ROSSA, 2010; PEREIRA, 2014).Para minimizar esse problema estudos recentes visam a utilização da enzima transglutaminase (TG) na indústria de alimentos, não só pela sua capacidade de modificar diversas proteínas, mas também pela melhoria nas características dos produtos que a enzima propõe ao produto final (YOKOYAMA; NIO; KIKUCHI, 2004).

A enzima TG, de acordo com seus critérios, tem a capacidade de modificar propriedades protéicas através de reações de transferências entre resíduos de glutamina e 


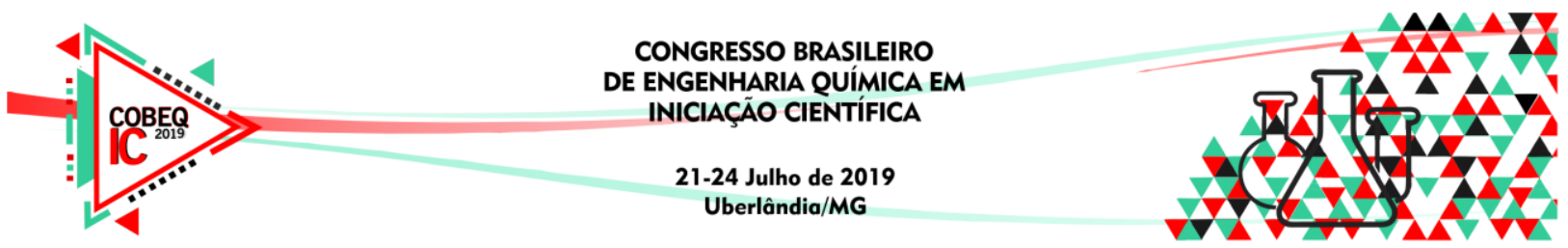

lisina (GAUCHE 2007). Tanto as caseínas quanto as proteínas do soro são consideradas bons substratos doadores e receptores para a TG (ROSSA, 2010).

Trabalhos na literatura mostram que a enzima TG quando aplicada em sorvetes com baixo teor de gordura e açúcar, modifica as suas propriedades promovendo características semelhantes à dos sorvetes com maior teor de gordura e com açúcares. Além disso a enzima pode ser aplicada no produto sem afetar as propriedades funcionais do mesmo (FARIA, 2010; ROSSA, 2010; GAUCHE, 2007).

O objetivo desse trabalho foi avaliar as características físico-químicas do sorvete, com baixo e alto teor de gordura, após aplicação da enzima transglutaminase (TG).

\section{MATERIAIS E MÉTODOS}

\subsection{Preparação do sorvete}

O sorvete utilizado nesse trabalho foi elaborado no laboratório de Análise Sensorial da Universidade Federal de Uberlândia campus Patos de Minas. A enzima transglutaminase (MTGase) foi gentilmente fornecida pela Ajinomoto (Ajinomoto. São Paulo. SP, Brasil) com atividade de $106 \mathrm{U}$ g-1. As demais matérias-primas foram adquiridas no mercado local.

As formulações desenvolvidas estão apresentadas na tabela 3. As variáveis estudadas foram teor de gordura e concentração de enzima. A variação no teor de gordura foi obtido utilizando leite com diferentes composições de gordura: leite integral (4,6\% de gordura) e desnatado (0,9 \% de gordura). As concentrações de enzimas estudadas foram: sem enzima e com enzimas $(0,5 \%$ e $1,0 \%)$, totalizando 6 diferentes formulações. Os ensaios foram realizados em duplicata e analise físico-química de cada ensaio em triplicata.

Na elaboração do sorvete, inicialmente sob agitação o leite fluido foi pré-aquecido à $50^{\circ} \mathrm{C}$, e logo em seguida adicionou-se o leite em pó, açúcar e o preparo pra sorvete. A mistura foi submetida a um tratamento térmico de $75 \pm 1{ }^{\circ} \mathrm{C}$ por 25 minutos. Adicionou-se a super liga e realizou-se a homogeneização da calda por $5 \mathrm{~min}$. Mantiveram-se as amostras em congelador $\left(-5^{\circ} \mathrm{C}\right)$ por 24 horas, a fim de promover a etapa de maturação. Posteriormente, realizou-se o batimento da calda com o emulsificante (Emustab) por 7 minutos em uma batedeira Planetária Arno SX80 Deluxe.

Para acondicionamento, as amostras foram embaladas e mantidas em um freezer à -22 ${ }^{\circ} \mathrm{C}$, para o congelamento final. Para os sorvetes com a adição de enzima foram preparados conforme descrito anteriormente, modificando algumas etapas: após o tratamento térmico a calda foi resfriada a $40^{\circ} \mathrm{C}$ para adição enzima, lembrando que a quantidade de enzima adicionada foi de acordo com a quantidade de proteína presente no mesmo. Nesta etapa, para atuação da enzima, a calda foi agitada por 90 minutos, sendo inativada logo após, a temperatura de $75^{\circ} \mathrm{C}$ por 15 segundos. Após essa inativação foram adicionados os demais ingredientes, e seguiu o processamento do sorvete sem adição de enzima. 


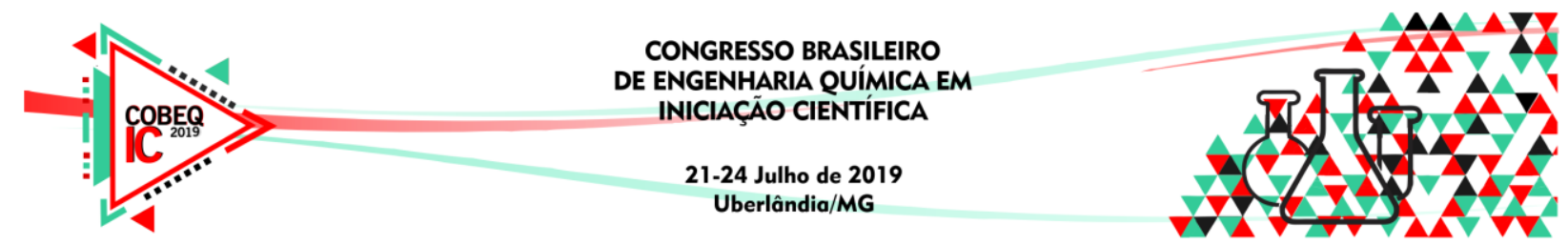

\subsection{Textura}

A avaliação instrumental da textura foi realizada por meio de um texturômetro digital (Stable Micro System, modelo TAXT2i texture analyser), utilizando-se uma sonda (probe) de cilindro com $50 \mathrm{~mm}$ de diâmetro (compressão). As amostras foram mantidas a $-22^{\circ} \mathrm{C}$ até serem cortadas em cubos de 2 × 2 × $2 \mathrm{~cm}$ e comprimidas a uma velocidade de $5 \mathrm{~mm} / \mathrm{s}$ (penetração), que equivale a $50 \%$, isto é, $1 \mathrm{~cm}$ de compressão.

\section{RESULTADOS E DISCUSSÃO}

A textura está diretamente relacionada com a aceitação do consumidor, sendo elas bastante influenciadas pela gordura e estrutura das proteínas (ROSSA, 2010). Os resultados do teste de textura, apresentados na Figura 12, mostram que houve diferença significativa ( $p>0,05)$ entre as amostras SED e SEI, respectivamente, desnatado com baixo teor de gordura e integral com alto teor de gordura. Observa-se que a maior quantidade de gordura favoreceu a textura do sorvete, sendo o valor de textura de $800 \mathrm{~g}$, próximo da metade do valor obtido para o sorvete desnatado. Isto indica que a gordura melhorou as características sensoriais, tornando o sorvete com textura macia e cremosa.

Figura 1 - Firmeza dos sorvetes obtidas através de análises de textura experimental expresso em força $(g)$.

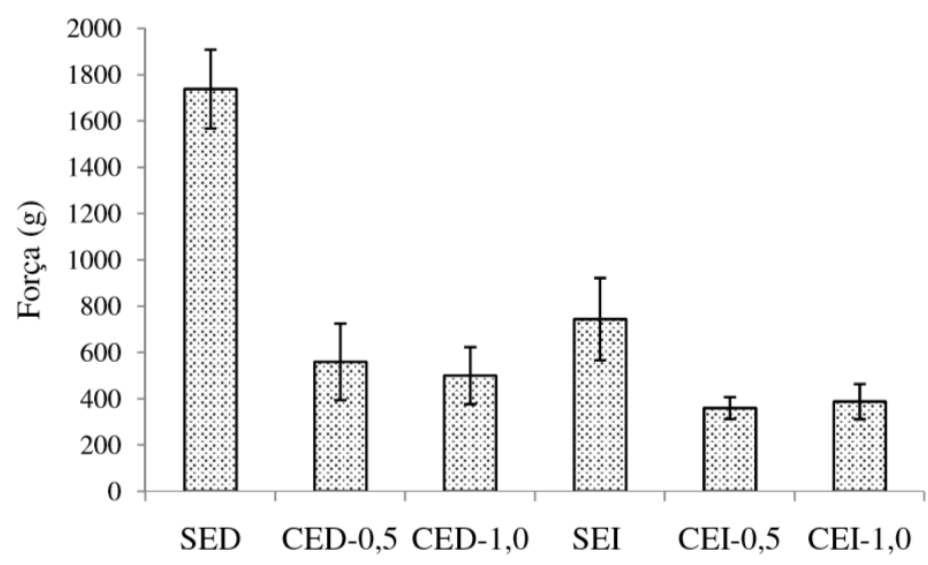

Pode ser explicado também pelo fato da capacidade de retenção de água, que pode ser aumentada pela desnaturação das proteínas, causado pelo aumento de temperatura, essa retenção de água estabiliza a interface ar/água. Sendo assim, a incorporação de proteínas na formulação, especialmente na sua forma desnaturada, tem como função diminuir a água livre disponível para o congelamento reduzindo a formação de cristais de gelo aumentando as bolhas de ar. Grandes quantidades de gelo no sorvete tornam o mais duro e proporciona maior firmeza (DANESH et al., 2017; PEREIRA, 2014).

Comparando as amostras que tiveram adição de enzima, observou-se que a adição de enzima nos sorvetes com baixo teor de gordura (CED0,5\% e CED1,0\%) melhorou a sua textura, mas também houve melhora no sorvete com alto teor de gordura (CEI0,5\% e 


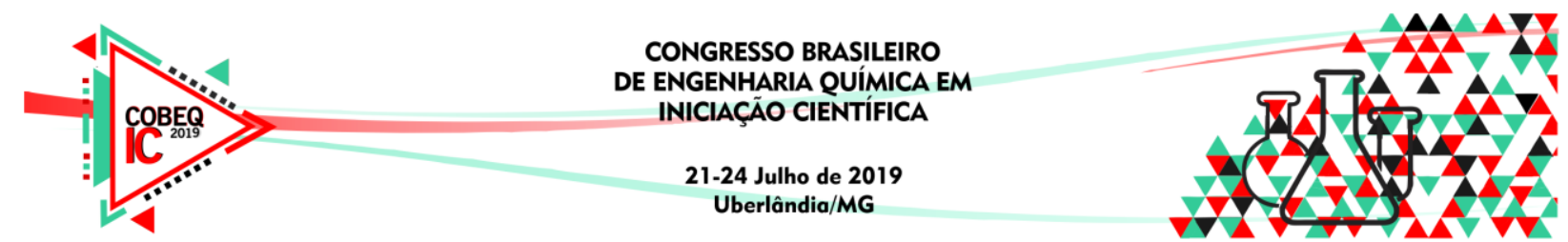

CEI1,0\%), não apresentando diferença significativa entre as amostras.. Assim, a adição de enzima melhora a textura de sorvetes com baixo teor de gordura e com alto teor de gordura. Danesh et al. (2017) realizaram testes quanto às propriedades físicas e sensoriais em sorvetes com a adição de transglutaminase e proteína de soro. Neste estudo, os autores observaram que os sorvetes fortificados com proteínas de soro, tratados com MTGase e com redução de gordura, apresentaram maior viscosidade, o que reduz a dureza do sorvete.

Ainda comparando as amostras que tiveram adição de enzima, a variação da concentração de enzima não teve diferença significativa $(\mathrm{p}>0,05)$ para a textura. Conforme Pereira (2014), a quantidade de enzima utilizada é de extrema importância para que não ocorra polimerização de proteína excessiva, pois o excesso dessa ação enzimática causa uma textura frágil e quebradiça. Altas concentrações de enzima prejudicam na formação de gel, que perde a capacidade de reter água, inibindo o desenvolvimento de uma rede uniforme de polimerização. Sendo assim, a quantidade de enzima apropriada depende de cada tipo de alimento.

Além da quantidade de enzimas, em decorrência do aquecimento do leite ocorre a desnaturação das proteínas do leite, favorecendo a atuação da MTGase na conversão do substrato em produto. A enzima atua na formação de ligações cruzadas, podendo reduzir a cristalização do gelo, o que torna o sorvete mais macio. Assim, proteínas desnaturadas interagem entre si formando uma rede proteica levando a redução da cristalização do gelo, ocasionando uma diminuição da dureza no sorvete, ou seja, um aumento na viscosidade (DANESH et al., 2017; PEREIRA, 2014).

\section{CONCLUSÃO}

Conforme observado neste trabalho, as diferentes concentrações de enzimas não apresentaram diferenças significativas na análise textura. Assim, pode-se dizer que é preferível utilizar a concentração de $0,5 \%(\mathrm{U} / \mathrm{g})$ no preparo de sorvetes, pois obtêm bons resultados com menor custo. Houve diferença entre as formulações realizadas com leite fluido e em pó integral e desnatado, principalmente para amostras sem enzimas. Sendo assim, a enzima transglutaminase melhorou principalmente o sorvete desnatado, com baixo teor de gordura $(0,9 \%)$, mostrando que seu uso é eficaz e necessário em sorvete com alto e baixo teor de gordura, pois confere maciez.

\section{AGRADECIMENTOS}

Os autores gostariam de agradecer a FAU-UFU, ao CNPq, à CAPES, à FAPEMIG (Brasil) e à Universidade Federal de Uberlândia pelo apoio durante todo o trabalho.

\section{REFERÊNCIAS}

DANESH, E; GOUDARZI, M; JOOYANDEH, H. Short communication: Effect of whey protein addition and transglutaminase treatment on the physical and sensory properties of reduced-fat ice cream. Journal Of Dairy Science, [s.1.], v. 100, n. 7, p.5206-5211, jul. 2017. 


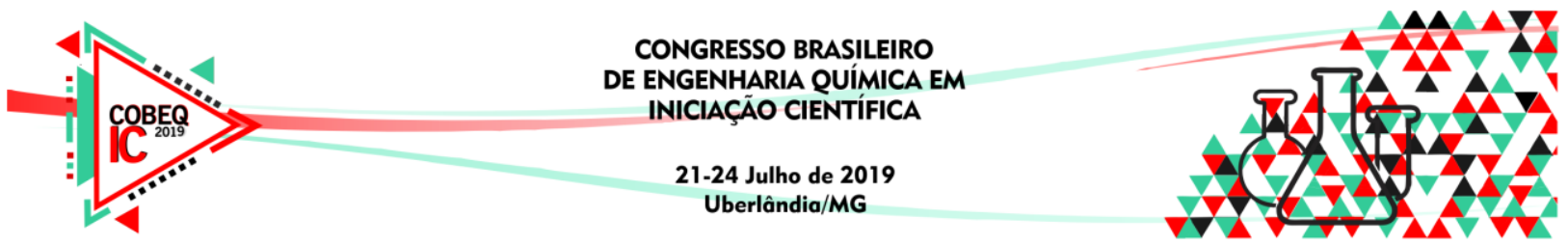

FARIA, D. S. Estudo dos efeitos de aplicação de transglutaminase em bebida láctea fermentada com alto conteúdo de soro. 2010. 118f. Dissertação (Mestrado em Engenharia de processos Químicos e Bioquímicos) - Centro Universitário do Instituto Mauá de Tecnologia, São Caetano do Sul, 2010. Disponível em: https://link.springer.com/ article/10.1007/s00217006-0401-2. Acesso em: 21 de outubro de 2017.

GAUCHE, C. Polimerização de proteínas do soro de leite por transglutaminase e propriedades físicas de iogurte elaborado após tratamento enzimático. 2007. 120 f. Dissertação (Mestrado) - Curso de Ciência dos Alimentos, Universidade Federal de Santa Catarina, Florianópolis, 2007.

GOFF, H. D; HARTEL, R. W. Ice Cream.7.ed. Nova York: Springer Science, 2013. 462 p.

PEREIRA, C. Propriedades funcionais de sorvete de morango diet com adição da enzima lactase e transglutaminaseotimizada através da metodologia de superfície de resposta. 2014. 321 f. Tese (Doutorado) - Curso de Centro de Ciências Agrárias, Universidade Federal de Santa Catarina, Florianópolis, 2014.

ROSSA, P. N. et al. Optimization of microbial transglutaminase activity in ice cream using response surface methodology. Lwt - Food Science And Technology, [s.l.], v. 44, n. 1, p.2934, jan. 2012. Elsevier BV. http://dx.doi.org/10.1016/j.lwt.2010.06.013.

YOKOYAMA, K.; NIO, N.; KIKUCHI, Y..Properties and applications of microbial transglutaminase. Applied Microbiology And Biotechnology, [s.1.], v. 64, n. 4, p.447-454, 1 maio 2004. Springer Nature. http://dx.doi.org/10.1007/s00253-003-1539-5. 